\title{
ASSOCIATION BETWEEN ENTAMOEBA HISTOLYTICA/DISPAR AND HELICOBACTER PYLORI INFECTIONS IN PATIENTS WITH GASTROINTESTINAL COMPLAINTS
}

\section{By}

\begin{abstract}
AZZA K. AHMED ${ }^{1}$, AMANY M. KAMAL ${ }^{1^{*}}$, NAWRAS M. EI-SAGHIER MOWAFY ${ }^{1,2}$, EPTESAM E. HASSAN ${ }^{3}$, HEBA AHMED OSMAN ${ }^{4}$ and SANAA SHAKER ALY ${ }^{5}$ Department of Parasitology ${ }^{1}$, Faculty of Medicine, Minia University, Department of Medical Parasitology ${ }^{2}$, Faculty of Medicine, Umm Al-Qura University, Makkah, KSA, Department of Public Health and Preventive Medicine ${ }^{3}$, Faculty of Medicine, Minia University, Minia $61519^{1,3}$, Egypt, Departments of Tropical Medicine and Gastroenterology ${ }^{4}$, and Clinical and Chemical Pathology ${ }^{5}$, Faculty of Medicine, South Valley University ${ }^{4,5}$, Qena, Egypt. ("Correspondence: AmanyKamal20002000@yahoo.com)
\end{abstract}

\section{Abstract}

This research studied the prevalence of different intestinal parasitic infections amongst $H$. pylori infected patients and assessed the association impact in the pathogenesis of $H$. pylori infection at the Tropical Medicine and Gastroenterology outpatient clinic, South valley University Hospitals. A total of 80 stool samples were collected. $H$. pylori infection was diagnosed by detecting the $H$. pylori antigen in stool. Accordingly, patients were divided into 2 groups: H. pylori positive cases (group I) and was 50 cases $(62.5 \%)$ and $H$. pylori negative cases (group II). H. pylori positive cases were subjected to upper endoscopy. There was a significant association between parasitic infections and $H$. pylori in patients with gastrointestinal complaints $(P \leq 0.005)$. Entamoeba histolytica/dispar $(55.5 \%)$ was the commonest parasite detected in $H$. pylori positive cases. Upper gastrointestinal endoscopy of the stomach showed characteristic mucosal pattern (mosaic appearance with focal hyperemic area), indicated $H$. pylori infection.

Key words: Egypt, Helicobacter pylori, Intestinal parasites, Entamoeba histolytica/dispar.

\section{Introduction}

Helicobacter pylori (H. pylori) are gramnegative bacilli responsible for chronic gastritis. H. pylori being recognized as strongly associated with gastric and duodenal ulcers in all age groups (Mutaz and Carmen, 2015). H. pylori produce a sufficient amount of active urease enzyme to survive the acidic environment of the stomach (Smoot, 1997), and some enzymes with destructive effect to the epithelial lining of the stomach as: protease enzyme, vacuolating cytotoxin A (VacA) and phospholipases (Cameron et al, 2001)

Poor socioeconomic condition is a major risk factor for acquiring not only $\mathrm{H}$. pylori infection but also parasitosis (Hotez et al, 2004). Moreover, prevalence of $H$. pylori infection is much higher in developing countries than in developed ones (Cave, 1997; Elsaied et al, 2009, Eldash et al, 2013).

Gastrointestinal tract parasites may induce mild, acute or chronic infections (Mazigo et $a l, 2010)$. The intestinal parasites cause gas- trointestinal symptoms such as diarrhea, dysentery, vomiting, lack of appetite and abdominal distention (Garcia, 2004). In Egypt, Entamoeba histolytica was the most prevalent protozoan infection followed by Giardia lamblia infection (Bakr et al, 2009; Zaytoun et al, 2013).

In Egypt, there is more or less little information about the magnitude of parasitic infections amongst patients infected with $H$. pylori and suffering from recurrent GIT symptoms. No doubt, differentiation of parasitic agents plays an important role treatment.

This study aimed to examine the prevalence of different intestinal parasitic infections amongst $H$. pylori infected patients and to assess the impact of this association in the pathogenesis of $H$. pylori infection at the Tropical Medicine and Gastroenterology Outpatient Clinic, South Valley University Hospital, Qena Governorate, Egypt.

\section{Material and methods}

The study included 80 patients attended the 
Tropical Medicine \& Gastroenterology, Department, Faculty of Medicine, South Valley University, during the period from April 2015 to September 2016. They suffered from either upper GIT symptoms (heartburn, vomiting, hematemesis \& melena) or of upper along with lower GIT symptoms (diarrhea, diarrhea alternating with constipation, abdominal distention, dysentery \& tenesmus). Sheets were filled out on each patient. A patient with any of the gastric surgery, gastric malignancy, severe hepatic, renal, and cardiopulmonary impairment, bleeding tendency, smoking, addictive tea or coffee, on non-steroidal anti-inflammatory drugs, antiplatelet agents, anticoagulants, steroids, antibiotics, proton pump inhibitors or bismuth within last 30 days was excluded.

Stool examination: Two fresh stool samples were collected from each patient at the time of enrollment in the study. The first sample diagnosed $H$. pylori by detecting antigen using $H$. pylori stool antigen test (One step $H$. pylori antigen test device; ACON Laboratories Inc., San Diego, CA, USA) according to manufacturer's directions (Silva et al, 2010). So, patients were divided into 2 groups: $H$. pylori positive cases (GI) and $H$. pylori negative cases (GII).

The second stool sample was transferred to the Clinical Pathology laboratory, Faculty of Medicine to be examined immediately by different techniques for parasitic infections. In the laboratory, slides were then prepared directly for wet mount in saline as well as in iodine and then were microscopically examined initially under low power then under high power. Finally the sample was concentrated by applying the formalin-ethyl acetate technique (Dubey et al, 1990). The iodine stained slides were prepared and examined microscopically. Fixed smears were stained with Modified Ziehl-Neelsen stain (ElShazly et al, 2006) and Giemsa stain (Garcia, 2004). Also, stool culture for nematode larvae on agar plates was done for detection of S. stercoralis or hookworm larvae (Knopp et al, 2008).
Endoscopic examination: To assess the degree of severity of gastritis related to $H$. pylori infection and to determine the role of parasitic infection in changing the mucosal pattern of the stomach in these patients, all patients included in the study who were proved to have $H$. pylori positive stool antigen were subjected to upper GIT endoscopy after conscious sedation using $5 \mathrm{mg}$ intravenous Midazolam, with upper video gastroduodenoscopes (EPK-I 5000 Olympus Europe, Hamburg, Germany).

Ethical considerations: Verbal consent was obtained from the patients. All procedures were conducted according to the ethical standards approved by the Institutional Human Ethics Committee, Faculty of Medicine, South Valley University.

Statistical analysis: Data were entered and analyzed by SPSS 19, quantitative data presented as mean and standard deviation, qualitative data presented as frequency, chi square, $\mathrm{z}$ test and one way ANOVA test. $\mathrm{P}$ value of less than 0.05 considered as cut off for significance.

\section{Results}

H. pylori infection was detected in $50 / 80$ patients $(62.5 \%)$. The prevalence of intestinal parasitic infection in $H$. pylroi positive cases (GI) was 36/50 (72\%) versus $13 / 30$ (43.3\%) in $H$. pylori negative cases (GII) were significant $(P=0.005)$. Intestinal parasites detected included Entamoeba histolyticaldispar $(55.5 \%)$, Blastocystis hominis (27.7\%), Giardia lamblia (38.8\%), Ascaris lumbricoides (19.4\%) and Enterobius vermicularis $(2.7 \%)$. Eight samples with mixed infections: E. histolytica/dispar and B. hominis in three samples, E. histolytica/dispar and $E$. vermicularis in one sample, $G$. lamblia and B. hominis in two sample, A. lumbricoides and $B$. hominis in two samples. There was significant association between $E$. histolyticaldispar and $H$. pylori $(P<0.05)$. 
Table 1: Prevalence of intestinal parasites amongst $H$. pylori positive and $H$. pylori negative patients.

\begin{tabular}{|c|c|c|c|c|}
\hline \multirow[b]{2}{*}{ Intestinal parasites } & GI positive patients $(n=50)$ & G II negative patients $(n=30)$ & \multirow[b]{2}{*}{$\mathrm{Z}$ test } & \multirow[b]{2}{*}{$P$ value } \\
\hline & No $(\%)$ & No $(\%)$ & & \\
\hline 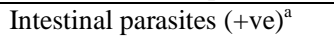 & $36(72)$ & $13(43.3)$ & 4.4 & $0.005^{*}$ \\
\hline Entameba histolytica/dispar & $20(55.5)$ & $2(15.3)$ & 3.3 & $0.003 *$ \\
\hline Blastocystis spp. & $10(27.7)$ & $8(61.5)$ & 2.1 & $0.01 *$ \\
\hline Giardia lambia & $14(38.8)$ & $3(23.1)$ & 0.9 & 0.1 \\
\hline Cryptosporidium spp. & $0(0.00)$ & $5(23.3)$ & 2.9 & $0.001 *$ \\
\hline Ascaris lumbricoides & $7(19.4)$ & $2(38.5)$ & 1.3 & 0.08 \\
\hline Entrobiuos vermicularis & $1(2.7)$ & $0(0.00)$ & 0.5 & 0.3 \\
\hline Intestinal parasites (-ve) & $14(28)$ & $17(56.7)$ & 1.01 & 0.1 \\
\hline
\end{tabular}

\section{Discussion}

H. pylori colonizes gastric mucosa and one of the major cause of gastric ulcer, autoimmune gastritis, gastric cancer and $\mathrm{B}$ cell lymphoma of mucosa associated lymphoid tissue (Kusters et al, 2006). H. pylori stool antigen test has the advantage of being directed noninvasive (Sabbi et al, 2012).

The current study observed significant high prevalence of parasitic infection among $H$. pylori positive patients $(\mathrm{P}<0.005)$, as compared to $H$. pylori negative patients. This result was in concordance with few previous studies (El-Massry et al, 2003; Kazemian et al, 2014). H. pylori escaped the destructive effect of stomach acidity by neutralization, as it produces large amounts of urease enzyme which breaks down plasma urea in the stomach wall to ammonium ion. $H$. pylori proved risky infection by destroying stomach acidity (Smoot, 1997) an important body defense against ingested pathogens (Smith, 2003; David and William, 2006).

The present study showed a significant association between E. histolytical dispar and $H$. pylori infections $(P<0.05)$. This strong association is attributed to the fact that $H$. pylori has been found to affect the sensorymotor system of the gut including the colon, in addition to its urease enzyme neutralization effect on stomach acidity. Kazemian $e t$ al. (2014) in Iran among 37 children with $H$. pylori infection they reported G. lamblia and E. histolytica/dispar in $29.7 \%$, \& $10.8 \%$ respectively. Fouad et al. (2014) in Egypt stated that $H$. pylori, G. intestinalis and coeliac disease were common causes of dyspepsia and found G. intestinalis genotype A greatly associated with dyspeptic symptoms. Sabah et al. (2015) in Egypt among 72/140 with $H$. pylori co-infection with $E$. histolytica, or $G$. lamblia found $(51.4 \%)$, and added that $H$. pylori was about $70 \%$ in Tanta City in patients with different gastrointestinal symptoms. But, others found association between G. lamblia and H. pylori infections (Zeyrek et al, 2008; Escobar-Pardo et al, 2011), the present study did not show significant association $(\mathrm{P}>0.05)$. All these parasites are transmitted faeco-orally either directly or through consumption of food or water contaminated with their infective stages; prevalence rate of these parasitic infections mainly depends on sanitary conditions. Most patients were from rural areas with poor sanitary conditions and of low socioeconomic level which are major risk factors for acquiring both $H$. pylori and parasites (Cameron $e t$ $a l, 2001)$. H. pylori possibly act as an additional risk factor for those parasitosis.

In the present study, upper gastrointestinal endoscopy of stomach showed characteristic mucosal pattern of $H$. pylori that was mosaic appearance, with or without focal hyperemic areas that agreed with Yan et al. (2010) who reported that mosaic mucosal pattern of the stomach was an indicator for $\mathrm{H}$. pyloripositive gastritis. But, no difference in stomach mucosal pattern was detected among patients with or without parasitic infections.

\section{Conclusion}

G. lamblia triggers symptoms of functional dyspepsia. The study showed that $H$. pylori were a major risk factor for Entamoeba spp. co-infection in rural areas of Qena Governorate. This needs proper intervention to re- 
duce co-infection.

\section{References}

Bakr, IM, Arafa, NA, Ahmed, MA, Mostafa, MH, Mohamed, MK, 2009: Prevalence of intestinal parasitosis in a rural population in Egypt, and its relation to socio-demographic characteristics. J. Egypt. Soc. Parasitol. 39, 1:371-81.

Cameron, I, Marion, R, Billy, B, Brendan, D, 2001: Is Helicobacter pylori Infection in Childhood a Risk Factor for Gastric Cancer? Pediatr. 107, 2:373-80.

Cave, RD, 1997: How is Helicobacter pylori transmitted? Gastroenterology 113:S9 S14.

David, TJ, William, AP, 2006: Medical Parasitology. $9^{\text {th }}$ edition. Saunders Elsevier, NY.

Dubey, JP, Speer, CA, Fayer, R, 1990: Cryptosporidiosis of Man and Animals. Boca Raton, Florida, USA. CRC Press.

Eldash, HH, Bekhit, OE, Algameel, AA, 2013: Impact of Helicobacter pylori-giardiasis coinfection on children with recurrent abdominal pain. J. Egypt. Soc. Parasitol. 43, 2:509-16.

El-Massry, AM, Thabet, TM, Kassem, AN, Badr El-din, S, 2003: Helicobacter pylori infection among school children in Alexandria: Possible association with intestinal parasitic infections. Bull. High. Inst. Pub. Hlth. 33, 1:141-56.

Elsaied, NA, Abbas, AT, El-Beshbishi, SN, Elsheikha, HM, 2009: Increased Helicobacter pylori-associated pathology in outbred mice co-infected with schistosomiasis. Parasitol. Res. 105, 2:297-9.

El-Shazly, AM, Awad, SE, Sultan, DM, Sadek, GS, Khalil, HH, et al, 2006: Intestinal parasites in Dakahlia Governorate, with different techniques in diagnosing protozoa. J. Egypt. Soc. Parasitol. 36: 1023-1034.

Escobar-Pardo, ML, de Godoy, AP, Machado, RS, Rodrigues, D, Neto, U, et al, 2011: Prevalence of Helicobacter pylori infection and intestinal parasitosis in children of the Xingu Indian Reservation. J. Pediatr. (Rio J.) 87, 5:393-8. Fouad, SA, Esmat, S, Basyoni, MM, Farhan, MS, Kobaisi, MH, 2014: Molecular identification of Giardia intestinalis in patients with dyspepsia. Digestion 90, 1:63-71

Garcia, LS, 2004: Diagnostic Medical Parasitology. $4^{\text {th }}$ edition, ASM Press.

Hotez, PJ, Brooker, S, Bethony, JM, Bottazzi, ME, Loukas, A, 2004: Hookworm infection. New. Engl. J. Med. 351: 799-807.

Kazemian, H, Shavalipour, A, Mohebi, R,
Ghafurian, S, Aslani, S, et al, 2014: Estimation of the parasitic infection prevalence in children with Helicobacter pylori infection in Ilam City (2012-2013). Arch. Pediatr. Infect. Dis. 2(3): e15294. Doi: 10.852pedinfect.15259

Knopp, S, Mgeni, AF, Khamis, IS, Steinmann, P, Stothard, JR, et al, 2008: Diagnosis of soil-transmitted helminths in the era of preventive chemotherapy: effect of multiple stool sampling and use of different diagnostic techniques. PLoS. Negl. Trop. Dis. 2: e331.

Mazigo, H, Ambrose, EE, Zinga, M, Bahemana, E, Mnyone, LL, et al, 2010: Prevalence of intestinal parasitic infections among patients attending Bugando Medical Centre in Mwanza, north-western Tanzania: a retrospective study. Tanzania. J. Hlth. Res. 12:202-7.

Mutaz, IS, Carmen, C, 2015: Helicobacter Pylori Infection. Mdscape.com/article/929452-overview.

Sabah, AA, Gneidy, MR, Saleh, NM, 2015: Prevalence of Helicobacter pylori infection among adult patients with different gastrointestinal parasites in Tanta City district. J. Egypt. Soc. Parasitol. 45, 1:101-6.

Silva, JM, Villares, CA, Monteiro Mdo, Colaúto, $\mathrm{C}$, dos Santos, $\mathrm{AF}$, et al, 2010: Validation of a rapid stool antigen test for diagnosis of $\mathrm{Hel}$ icobacter pylori infection. Rev. Inst. Med. Trop. Sao Paulo. 52, 3:125-8.

Smith, JL, 2003: The role of gastric acid in preventing food-borne disease and how bacteria overcome acid conditions. J. Food. Prot. 66: 1292-303.

Smoot, DT, 1997: How does Helicobacte pylori cause mucosal damage? Direct mechanisms. Gastroenterology 113, 6:S31-50.

Yan, SL, Wu, ST, Chen, CH, Hung, YH, Yang, TH, et al, 2010: Mucosal patterns of Helicobacter pylori-related gastritis without atrophy in the gastric corpus using standard endoscopy. World. J. Gastroenterol. 16, 4:496-500.

Zaytoun, S SH, Abd Ella, OH, Ghweil, AAR, Hussien, SM, Ayoub, HA, et al, 2013: Prevalence of intestinal parasitosis among male youth in Qena Governorate (Upper Egypt), and its relation to socio-demographic characteristics and some morbidities. Life Sci. J. 10, 3:658-63.

Zeyrek, D, Zeyrek, F, Cakmak, A, Cekin, A, 2008: Association of Helicobacter pylori and giardiasis in children with recurrent abdominal pain. Turkiye. Parazitol. Derg. 32, 1:4-7. 